\title{
Post-saline infusion test aldosterone levels indicate severity and outcome in primary aldosteronism
}

\author{
Marianne Weigel ${ }^{1, *}$, Anna Riester ${ }^{2,{ }^{*}}$, Gregor Hanslik ${ }^{1}$, Katharina Lang ${ }^{3}$, \\ Holger S Willenberg ${ }^{4,5}$, Stephan Endres ${ }^{2}$, Bruno Allolio ${ }^{3}$, Felix Beuschlein ${ }^{2}$, \\ Martin Reincke ${ }^{2}$ and Marcus Quinkler ${ }^{1,6}$ \\ ${ }^{1}$ Clinical Endocrinology, Charité Campus Mitte, Charité University Medicine Berlin, Berlin, Germany, ${ }^{2}$ Medizinische \\ Klinik und Poliklinik IV, University Hospital Munich, Munich, Germany, ${ }^{3}$ Department of Internal Medicine I, \\ University Hospital Würzburg, Würzburg, Germany, ${ }^{4}$ Division for Specific Endocrinology, Medical Faculty, University \\ Duesseldorf, Duesseldorf, Germany, ${ }^{5}$ Division of Endocrinology and Metabolism, Rostock University Medical Center, \\ Rostock, Germany and ${ }^{6}$ Endocrinology in Charlottenburg, Stuttgarter Platz 1, D10627 Berlin, Germany \\ *(M Weigel and A Riester contributed equally to this work)
}

Correspondence should be addressed to M Quinkler

Email

marcusquinkler@t-online.de

\begin{abstract}
Objective: The saline infusion test (SIT) is widely used as a confirmatory test for primary aldosteronism (PA). SIT results are judged as follows: post-test aldosterone levels $<50 \mathrm{ng} / \mathrm{l}$ exclude PA, whereas levels $>50 \mathrm{ng} / \mathrm{l}$ confirm PA. We hypothesized that post-SIT aldosterone concentrations indicate the severity of PA and might predict outcome. Design: The study includes 256 PA patients of the German Conn's Registry who prospectively underwent SIT. The data of 126 patients with complete follow-up of $1.2 \pm 0.3$ years after diagnosis were analyzed. The patients were divided into two groups with post-SIT aldosterone levels of 50-100 ng/l (group $1 ; n=38$ ) and of $>100 \mathrm{ng} / \mathrm{l}$ (group $2 ; n=88$ ). Results: Patients in group 2 had a significantly shorter duration of hypertension ( 7.5 vs 11.7 years (median), $P=0.014$ ), higher systolic blood pressure (BP; $151 \pm 16$ vs $143 \pm 17 \mathrm{mmHg}, P=0.036$ ), lower serum potassium ( $3.3 \pm 0.6 \mathrm{vs} 3.5 \pm 0.4 \mathrm{mmol} / \mathrm{l}$, $P=0.006)$, higher 24-h urine protein excretion (7.4 vs $5.4 \mathrm{mg} / \mathrm{dl}$ (median), $P=0.012)$, and were more often female $(P=0.038)$. They showed more often unilateral disease $(P<0.005)$ with larger tumors $(14 \pm 10$ vs $7 \pm 10 \mathrm{~mm}, P=0.021)$, underwent more often adrenalectomy $(75 \%$ vs $37 \%, P<0.005)$, required a lower number of antihypertensive drugs after adrenalectomy $(1.2 \pm 1.2$ vs $2.5 \pm 1.4, P=0.001)$, had a faster normalization of urinary protein excretion (with medical treatment $P=0.049$; with $\operatorname{Adx} P<0.005)$ at follow-up, and more frequently underlying well-characterized mutation $(P=0.047)$. Conclusions: PA patients with post-SIT aldosterone levels of $>100 \mathrm{ng} / \mathrm{l}$ have a more rapid development of PA caused more frequently by unilateral disease with larger aldosterone-producing adenomas. However, this group of patients may have a significantly better outcome following specific treatment.
\end{abstract}

\section{Introduction}

Primary aldosteronism (PA) is the most common form of secondary hypertension and affects up to $10 \%$ of all hypertensive patients (1). Patients with PA have an increased risk of developing relevant comorbidities, e.g. vascular, cardiac, or cerebrovascular morbidities and renal insufficiency compared with other hypertensive patients
(C) 2015 European Society of Endocrinology Printed in Great Britain
$(2,3,4,5,6,7)$. Therefore, it seems mandatory to detect early patients with PA. The aldosterone-to-renin ratio (ARR) is recommended for screening patients with suspected PA (8). The guidelines of the Endocrine Society recommend that patients with a positive ARR measurement should undergo any of four confirmatory tests to 
confirm or exclude the diagnosis of PA (8). However, up to date there is no gold-standard confirmatory test for PA because all test performances have been evaluated only retrospectively, in relatively small series of patients and only in comparison with other tests rather than toward a conclusive diagnosis of PA (8). In Germany, the most widely used confirmatory test due to practicability, costs, and compliance is the saline infusion test (SIT). For the SIT post-infusion plasma aldosterone levels of $<50 \mathrm{ng} / 1$ largely exclude the diagnosis of PA, whereas levels of $>100 \mathrm{ng} / \mathrm{l}$ confirm PA. Values between 50 and $100 \mathrm{ng} / \mathrm{l}$ are often described as 'indeterminate' in older studies $(9,10,11,12)$, or interpreted as a mild or early form of PA.

To further investigate clinical, biochemical, and radiological features in PA with modest (post-SIT aldosterone levels of 50-100 ng/l) and with more substantial elevation of aldosterone levels (post-SIT >100 ng/l), we analyzed data from the German Conn's Registry, which was founded in 2006 to evaluate the diagnosis, treatment, and outcome of PA in Germany. Owing to the persistent lack of outcome data in PA patients, we were especially interested in the clinical outcome of these two groups with regard to adrenalectomy or medical treatment. We hypothesized that post-SIT aldosterone concentrations indicate the severity of PA and might predict outcome.

\section{Subjects and methods}

\section{Design and patients}

The German Conn's Registry (www.conn-register.de) is a multi-center database analyzing comorbidities and longterm outcome of patients with PA $(4,13,14)$. Since the initiation of the prospective phase in October 2008, all patients actively treated within the centers were entered in a common database after pseudonymization (15). The Ethics Committees of the University of Munich and of the participating centers approved the protocol. Data protection laws were strictly adhered to.

Clinical data at time of diagnosis were extracted from patients' charts including laboratory test results, initiation of mineralocorticoid antagonist treatment, surgical treatment, cardiovascular comorbidities, and BMI. Blood was generally drawn in the fasting state. Every 6 and 12 months the patients were seen for follow-up visits including a clinical examination, laboratory investigation, and cardiovascular examinations.

The diagnostic criteria for PA in this study were chosen according to the Endocrine Society practice guidelines (8). All patients included had an elevated ARR (in sitting position between 0800 and $1000 \mathrm{~h}$ ) and an abnormal confirmatory test $(4,16)$. Adjustment of medication before screening and confirmation was performed whenever possible, using $\beta$-blockers, central $\alpha$ - 2 agonists, angiotensin-converting enzyme inhibitors, angiotensin receptor blockers, diuretics withdrawn for at least 1 week, and mineralocorticoid antagonists at least for 4 weeks. The diagnosis of PA was centrally verified by review of all available data.

In the prospective phase of the German Conn's Registry, 256 PA patients underwent a recumbent SIT as confirmatory test. SIT was carried out with a 4-h saline infusion (2 1 i.v.) in supine position between 0800 and $1200 \mathrm{~h}$. Cortisol levels decrease during testing served as validation to exclude stress-related stimulation of aldosterone. A post-SIT aldosterone level >50 ng/l confirmed the diagnosis of PA.

Only patients with a complete data set at diagnosis and at follow-up were included. Sufficient data coverage was available for 126 prospectively recruited patients, who were included in the final analysis.

Subtype differentiation between aldosteroneproducing adenoma (APA) and bilateral adrenal hyperplasia was based on adrenal imaging (computed tomography or magnetic resonance imaging) and on adrenal vein sampling (AVS), the latter performed in $94 \%$ of the patients included $(n=118)$.

AVS was carried out after $2-3 \mathrm{~h}$ of resting in supine position between 0800 and $1200 \mathrm{~h}$ as described previously (17). Selective AVS was assumed for the purpose of this study, if cortisol of the adrenal vein was $100 \%$ higher than cortisol in the inferior vena cava (cortisol in adrenal vein/cortisol in inferior vena cava $\geq 2.0$ ). We used a lateralization index in AVS of $\geq 4$ to define unilateral aldosterone secretion.

AVS was successful in $94 \%$ of patients $(n=111)$. For further analysis, we distinguished between two patient groups in our prospective cohort: patients who had a postSIT aldosterone level between 50 and $100 \mathrm{ng} / \mathrm{l}$ (group 1), and patients with a post-SIT aldosterone level >100 ng/l (group 2).

Eighty patients in the whole cohort underwent adrenalectomy: 46 tumor samples from two centers (Munich and Berlin) were available for DNA isolation and sequencing. Tumor DNA was extracted and analyzed as part of recently published studies by Beuschlein et al. (18) and by Fernandes-Rosa et al. (19).

We defined the outcome as follows:

Cured (adrenalectomy patients only) $=$ serum potassium $>3.4 \mathrm{mmol} / \mathrm{l}$ and systolic blood pressure (BP) 
$<140 \mathrm{mmHg}$ and diastolic BP $<90 \mathrm{mmHg}$ and no antihypertensives.

Controlled (medically treated patients only) $=$ serum potassium $>3.4 \mathrm{mmol} / \mathrm{l}$ and systolic BP $<140 \mathrm{mmHg}$ and diastolic BP $<90 \mathrm{mmHg}$ and on therapy with mineralocorticoid (MR)-antagonists, but no other antihypertensives §.

Significantly improved $=$ normokalemia and systolic BP decrease by $\geq 10 \mathrm{mmHg}$ and decrease of antihypertensives by $\geq 1 \S$.

Slightly improved $=$ normokalemia and (systolic BP decrease by $\geq 10 \mathrm{mmHg}$ or decrease of antihypertensives by $\geq 1 \S)$.

No improvement $=$ persistent hypokalemia or no BP improvement according to the above criteria. §, MR antagonist was not counted as an antihypertensive.

\section{Statistical analyses}

Variables were assessed for normality by KolmogorovSmirnov test. Results are expressed as mean \pm s.D. if not stated otherwise. Differences between the two groups were assessed using Student's $t$-test for normally distributed variables and Mann-Whitney $U$ test for non-normally distributed variables. For paired data and for non-normally distributed variables, we used paired Wilcoxon's test.
For categorial variables and unpaired data we used $\chi^{2}$-test/Fisher's exact test and for categorial variables and paired data we used McNemar test. A $P$ value $<0.05$ was considered as significant. Statistical analysis was carried out using IBM SPSS Statistics 20.

\section{Results}

Of the 126 PA patients included in this analysis, $38 \mathrm{PA}$ patients had a post-SIT aldosterone level between 50 and $100 \mathrm{ng} / \mathrm{l}$ (group 1) and $88 \mathrm{PA}$ patients a post-SIT aldosterone $>100 \mathrm{ng} / \mathrm{l}$ (group 2). Patients of group 2 were significantly more often hypokalemic, had hypertension for a shorter duration, showed higher systolic BP, and a higher proteinuria at time of diagnosis (Table 1). Group 2 contained a higher proportion of female patients than group 1 and showed a significant higher rate of unilateral aldosterone secretion resulting in a higher rate of adrenalectomies (Table 2 ). In group 1 only 14 patients (37\%) had unilateral disease and were adrenalectomized. In comparison with the 66 patients $(75 \%)$ of group 2 who underwent adrenalectomy, patients of group 1 were significantly older, had lower potassium levels, and more antihypertensive drugs at follow-up (1.2 \pm 0.3 years) (Table 3 ). The tumor size on imaging was significantly larger in group 2 (Table 3 ).

Table 1 Clinical and biochemical parameters of 126 prospective PA patients at diagnosis (baseline) depending on post-SIT aldosterone values. Values are means \pm s.D. (median).

\begin{tabular}{|c|}
\hline $\begin{array}{l}\text { Duration of hypertension (years) } \\
\text { Age at PA diagnosis (years) } \\
\text { Male/female } \\
\text { 24-h systolic BP (mmHg) } \\
\text { 24-h diastolic BP }(\mathrm{mmHg}) \\
\text { Aldosterone (ng/l) } \\
\text { Pre-test } \\
\text { Post-test } \\
\text { Renin (ng/l) } \\
\text { Pre-test } \\
\text { Post-test } \\
\text { ARR } \\
\text { Pre-test } \\
\text { Post-test } \\
\text { GFR (MDRD) (ml/min per } 1.73 \mathrm{~m}^{2} \text { ) } \\
\text { Serum creatinine (mg/dl) } \\
\text { Serum potassium (mmol/l) } \\
\text { Protein in 24-h urine (mg/dl) } \\
\text { No. of antihypertensives } \\
\text { BMI (kg/m²) }\end{array}$ \\
\hline
\end{tabular}

\begin{tabular}{c} 
Group $1(n=38)$ \\
\hline $16.4 \pm 12.5(11.7)$ \\
$53.9 \pm 11.3$ \\
$29(76 \%) / 9(24 \%)$ \\
$143 \pm 17$ \\
$91.0 \pm 11.1$ \\
$183 \pm 68.3(174)$ \\
$72.5 \pm 15.0(72.3)$ \\
$4.56 \pm 3.62(3.90)$ \\
$3.07 \pm 2.39(2.76)$ \\
$81.7 \pm 73.6(41.9)$ \\
$44.0 \pm 40.3(26.1)$ \\
$91.5 \pm 24.4$ \\
$0.91 \pm 0.27(0.90)$ \\
$3.5 \pm 0.4$ \\
$19 \pm 63(5.40)$ \\
$1.7 \pm 1.2$ \\
$29 \pm 5$
\end{tabular}

\begin{tabular}{c}
\hline Group $2(n=88)$ \\
\hline $11.3 \pm 11.4(7.5)$ \\
$50.4 \pm 12.4$ \\
$50(57 \%) / 38(43 \%)$ \\
$151 \pm 16$ \\
$93.7 \pm 13.5$ \\
$304 \pm 189(247)$ \\
$220 \pm 120(178)$ \\
$4.45 \pm 5.08(2.40)$ \\
$3.19 \pm 4.07(1.80)$ \\
$184 \pm 312(87.8)$ \\
$176 \pm 251(117)$ \\
$87.0 \pm 23.2$ \\
$0.91 \pm 0.31(0.80)$ \\
$3.3 \pm 0.6$ \\
$38 \pm 91(7.40)$ \\
$2.0 \pm 1.1$ \\
$29 \pm 5$
\end{tabular}

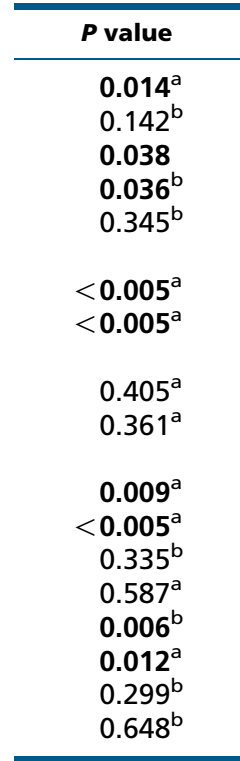

Group 1, post-SIT aldosterone 50-100 ng/l; group 2, post-SIT aldosterone $>100 \mathrm{ng} / \mathrm{l}$; BP, blood pressure; ARR, aldosterone-to-renin ratio; GFR, glomerular filtration rate.

a Mann-Whitney $U$ test.

${ }^{\mathrm{b}}$ Student's $t$-test. 
Table 2 Baseline features of 126 prospective PA patients depending on post-SIT aldosterone values.

\begin{tabular}{|c|c|c|c|}
\hline & Group $1(n=38)$ & Group $2(n=88)$ & $P$ value $^{a}$ \\
\hline Successful AVS & $35(92 \%)$ & $76(86 \%)$ & \\
\hline $\begin{array}{l}\text { Bilateral/unilat- } \\
\text { eral disease }\end{array}$ & $\begin{array}{c}19(50 \%) / \\
16(42 \%)\end{array}$ & $\begin{array}{l}18(21 \%) / \\
58(66 \%)\end{array}$ & 0.001 \\
\hline $\begin{array}{l}\text { Adrenalectomy, } \\
\text { yes/no }\end{array}$ & $\begin{array}{l}14(37 \%) / \\
24(63 \%)\end{array}$ & $\begin{array}{l}66(75 \%) / \\
22(25 \%)\end{array}$ & $<0.005$ \\
\hline
\end{tabular}

Group 1, post-SIT aldosterone levels of $50-100 \mathrm{ng} /$; group 2, post-SIT aldosterone levels of $>100 \mathrm{ng} / \mathrm{l} ; \mathrm{AVS}$, adrenal vein sampling. ${ }^{a} \chi^{2}$ test.

Twenty-four patients of group 1 and 22 patients of group 2 showed bilateral disease or refused adrenalectomy $(n=5)$ and, therefore, were put on medical therapy. At follow-up, medically treated patients of group 1 showed lower aldosterone levels but a similar ARR as group 2. Protein excretion of group 2 was reduced on medical therapy compared with the time at diagnosis, but was still higher than that of group 1 (Table 4 ).

BP normalization, normokalemia, and reduction in antihypertensive medication were more often achieved in group 2 than in group 1 (Fig. 1). Patients on medical therapy reached the outcome 'controlled' or 'significantly improved' only in 25 or $27 \%$ (groups 1 and 2 respectively). Of patients who underwent adrenalectomy, significantly $(P=0.038)$ more patients showed no improvement in group 1 compared with group 2 (Fig. 1). The overall outcome was significantly better $(P=0.01)$ in patients who underwent adrenalectomy compared with patients on medical therapy. ARR at screening and post-SIT aldosterone showed similar strength as predictors regarding outcome $(r=-0.188, P=0.045$ and $r=-0.182, P=0.041$ respectively). Post-SIT aldosterone levels remained significant $(P=0.046)$ after correction for main confounding variables (age, duration of hypertension, and BP).

Forty-six tumor samples from 80 adrenalectomies (58\%) were available (eight from group 1 and 38 from group 2). The frequency of well-defined somatic mutations was significantly higher $(P=0.047)$ in group 2 (22 of 38; 58\%) than in group 1 (one of eight; $13 \%$ ). In group 1 , only one tumor revealed a mutation in the $K C N J 5$ gene, whereas 17 tumors of group 2 showed a mutation in the KCNJ5 gene (45\%), one in the CACNA1D gene (3\%), three in the ATP1A1 gene (8\%), and one in $A T P 2 B 3$ gene $(3 \%)$.

\section{Discussion}

Mulatero et al. (20) had demonstrated that the SIT is a reasonably reliable alternative to the more time demanding and expensive fludrocortisone suppression test for the confirmation of $\mathrm{PA}$, showing a specificity of $84 \%$ and sensitivity of $88 \%$ with a cutoff value of $50 \mathrm{ng} / \mathrm{l}$.

Table 3 Clinical and biochemical parameters of 80 prospective PA patients $1.2 \pm 0.3$ years after adrenalectomy (follow-up) depending on post-SIT aldosterone values at diagnosis. Values are means \pm s.D. (median).

\begin{tabular}{l}
\hline After ADX \\
\hline Age at follow-up visit \\
Aldosterone (ng/l) \\
Renin (ng/l) \\
ARR \\
24-h systolic/diastolic BP $(\mathrm{mmHg})$ \\
GFR (MDRD) (ml/min per $\left.1.73 \mathrm{~m}^{2}\right)$ \\
Serum creatinine (mg/dl) \\
Serum potassium (mmol/l) \\
Protein in 24-h urine (mg/dl) \\
No. of antihypertensives \\
Tumor size according to pathological \\
report (mm) \\
Tumor size according imaging (mm) \\
No. of patients with mutation \\
KCNJ5 \\
CACNA1D \\
ATP1A1/ATP2B3
\end{tabular}

\begin{tabular}{c}
\hline Group $1(10 \mathrm{~m} / 4 \mathrm{f})$ \\
\hline $58 \pm 12$ \\
$90 \pm 73(68)$ \\
$39 \pm 77(10)$ \\
$35 \pm 75(12)$ \\
$133 / 84 \pm 17 / 10$ \\
$77 \pm 24$ \\
$1.1 \pm 0.4$ \\
$4.0 \pm 0.4$ \\
$4.9 \pm 2.1(5.0)$ \\
$2.5 \pm 1.4$ \\
$16 \pm 11(n=10) ; n=1 \mathrm{NH} ;$ \\
$n=3 \mathrm{ND}$ \\
$7 \pm 10(n=12) ; n=2 \mathrm{ND}$ \\
1 of 8 \\
1 \\
0 \\
$0 / 0$
\end{tabular}

\begin{tabular}{|c|c|}
\hline Group $2(37 \mathrm{~m} / 29 \mathrm{f})$ & $P$ value \\
\hline $\begin{array}{c}50 \pm 12 \\
71 \pm 46(55) \\
20 \pm 24(10) \\
10 \pm 15(6) \\
134 / 83 \pm 12 / 9 \\
75 \pm 23 \\
1.1 \pm 0.3 \\
4.3 \pm 0.5 \\
5.6 \pm 3.2(5.0) \\
1.2 \pm 1.2 \\
25 \pm 18(n=49) ; n=1 \mathrm{NH} ; \\
n=16 \mathrm{ND} \\
14 \pm 10(n=64) ; n=2 \mathrm{ND} \\
22 \text { of } 38 \\
17 \\
1 \\
3 / 1\end{array}$ & $\begin{array}{l}0.032^{\mathrm{a}} \\
0.536^{\mathrm{b}} \\
0.438^{\mathrm{b}} \\
0.244^{\mathrm{b}} \\
0.873 / 0.763^{\mathrm{a}} \\
0.800^{\mathrm{a}} \\
0.720^{\mathrm{a}} \\
0.027^{\mathrm{a}} \\
0.788^{\mathrm{b}} \\
0.001^{\mathrm{a}} \\
0.135^{\mathrm{a}} \\
0.021^{\mathrm{a}} \\
0.047^{\mathrm{c}}\end{array}$ \\
\hline
\end{tabular}

Group 1, post-SIT aldosterone levels of 50-100 ng/l; group 2, post-SIT aldosterone levels of >100 ng/l; ARR, aldosterone-to-renin ratio; BP, blood pressure; GFR, glomerular filtration rate; $\mathrm{NH}$, nodular hyperplasia; ND, no data available.

${ }^{a}$ Student's $t$-test.

${ }^{\mathrm{b}}$ Mann-Whitney $U$ test.

'Fisher's exact test. 
Table 4 Clinical and biochemical parameters of 46 prospective PA patients after $1.2 \pm 0.3$ years of medical therapy (follow-up) depending on post-SIT aldosterone values at diagnosis. Values are means \pm s.D. (median).

\begin{tabular}{l}
\hline Medical therapy \\
\hline Age at follow-up visit \\
Aldosterone (ng/l) \\
Renin $(\mathrm{ng} / \mathrm{l})$ \\
ARR \\
24-h systolic/diastolic BP $(\mathrm{mmHg})$ \\
GFR (MDRD) (ml/min per $\left.1.73 \mathrm{~m}^{2}\right)$ \\
Serum creatinine $(\mathrm{mg} / \mathrm{dl})$ \\
Serum potassium $(\mathrm{mmol} / \mathrm{l})$ \\
Protein in $24-\mathrm{h}$ urine $(\mathrm{mg} / \mathrm{dl})$ \\
No. of additional antihypertensives \\
MR antagonist (daily dose in $\left.\mathrm{mg}^{\mathrm{s}}\right)$ \\
Spironolactone \\
Eplerenone \\
Dose unknown $(n)$
\end{tabular}

\begin{tabular}{c}
\hline Group $1(19 \mathrm{~m} / 5 \mathrm{f})$ \\
\hline $53 \pm 11$ \\
$194 \pm 119(151)$ \\
$21 \pm 27(10)$ \\
$34 \pm 43(13)$ \\
$138 / 84 \pm 15 / 6(136 / 83)$ \\
$80 \pm 22$ \\
$1.0 \pm 0.4(1.00)$ \\
$4.1 \pm 0.5$ \\
$5.6 \pm 2.7(5.1)$ \\
$1.7 \pm 1.0$ \\
$43 \pm 19(n=18)$ \\
$80 \pm 45(n=5)$ \\
1
\end{tabular}

\begin{tabular}{c}
\hline Group $2(13 \mathrm{~m} / 9 \mathrm{f})$ \\
\hline $56 \pm 13$ \\
$434 \pm 348(354)$ \\
$41 \pm 71(13)$ \\
$35 \pm 36(25)$ \\
$138 / 86 \pm 26 / 16$ \\
$73 \pm 27$ \\
$1.1 \pm 0.3(0.9)$ \\
$4.1 \pm 0.5$ \\
$11.7 \pm 12.9(7.0)$ \\
$1.9 \pm 1.4$ \\
$49 \pm 22(n=20)$ \\
$-(n=0)$ \\
2
\end{tabular}

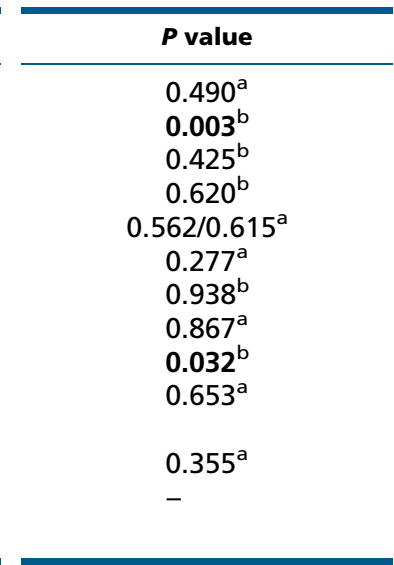

Group 1, post-SIT aldosterone levels of 50-100 ng/l; group 2, post-SIT aldosterone levels of $>100 \mathrm{ng} / \mathrm{l} ; \mathrm{ARR}$, aldosterone-to-renin ratio; BP, blood pressure; GFR, glomerular filtration rate.

astudent's $t$-test.

bMann-Whitney $U$ test.

'MR antagonist was not counted as an antihypertensive.

Accordingly, SIT is the most widely used confirmatory test for PA in many countries including Germany. In addition to the SIT, the patients in our prospective cohort underwent AVS to differentiate between uni- and bilateral disease. Thereby, we were able to show that $42 \%$ of patients with a post-SIT aldosterone levels between 50 and $100 \mathrm{ng} / \mathrm{l}$ had unilateral disease. Furthermore, our analysis indicates that patients with post-SIT aldosterone levels of $>100 \mathrm{ng} / \mathrm{l}$ had more severe PA with faster development of hypertension, higher systolic BP, lower serum potassium, and higher 24-h urine protein excretion at diagnosis. Importantly, in this group, the percentage of patients with unilateral PA was significantly higher than that in the group with post-SIT aldosterone levels of $50-100 \mathrm{ng} / \mathrm{l}$. This is in accordance to a previous small study showing that patients with APA displayed a smaller reduction in aldosterone levels in SIT compared with patients with bilateral adrenal hyperplasia (20). Another study had shown that patients with higher preoperative $\mathrm{BP}$ experienced a greater decrease in $\mathrm{BP}$ after adrenalectomy (21).

We found more patients in the group with post-SIT aldosterone level $>100 \mathrm{ng} / \mathrm{l}$, who were tested positive for somatic mutations in the removed APA compared with operated patients with a post-SIT aldosterone level of 50-100 ng/l. Previously published data have demonstrated that patients with KCNJ5 mutations are more frequently female and are diagnosed at a younger age $(19,22)$. This is in accordance with our cohort data, showing a higher percentage of female patients in the group with post-SIT aldosterone level $>100 \mathrm{ng} / \mathrm{l}$, and a higher percentage of KCNJ5 mutations.

Interestingly, patients with post-SIT aldosterone level of $>100 \mathrm{ng} / \mathrm{l}$, despite their more severe form of hypertension, responded better to specific therapy than those with a post-SIT aldosterone level of 50-100 ng/l: specifically, 1 year following therapy, they had faster normalization of urinary protein excretion and a better outcome, as defined by serum potassium and BP normalization and no or reduced antihypertensive drugs. For patients with post-SIT aldosterone levels of $50-100 \mathrm{ng} / \mathrm{l}$, at least one of three parameters improved following adrenalectomy in 50\% (vs $77 \%$ ) and after medical therapy in $71 \%$ (vs $82 \%$ ) respectively. Accordingly, the cure rate following adrenalectomy (defined as serum potassium $>3.4 \mathrm{mmol} / \mathrm{l}+\mathrm{BP}$ $<140 / 90 \mathrm{mmHg}+$ no antihypertensive drugs) was only $32 \%$ in the high aldosterone group and $7 \%$ in the low aldosterone group respectively. Similarly, a controlled status after medical therapy (defined as serum potassium $>3.4 \mathrm{mmol} / \mathrm{l}+\mathrm{BP}<140 / 90 \mathrm{mmHg}+$ on therapy with MR-antagonists, but no other antihypertensive drugs) was achieved in $14 \%$ in the high aldosterone group and $4 \%$ in the low aldosterone group respectively. The better outcome in the group with post-SIT aldosterone levels of $>100 \mathrm{ng} / \mathrm{l}$ might be mostly driven by the higher rate of KCNJ5 mutations with higher aldosterone levels, which generally show a better surgical outcome. This might also explain the finding of a recent study describing a better clinical course in patients with the presence of an adenoma rather than hyperplasia (23). 

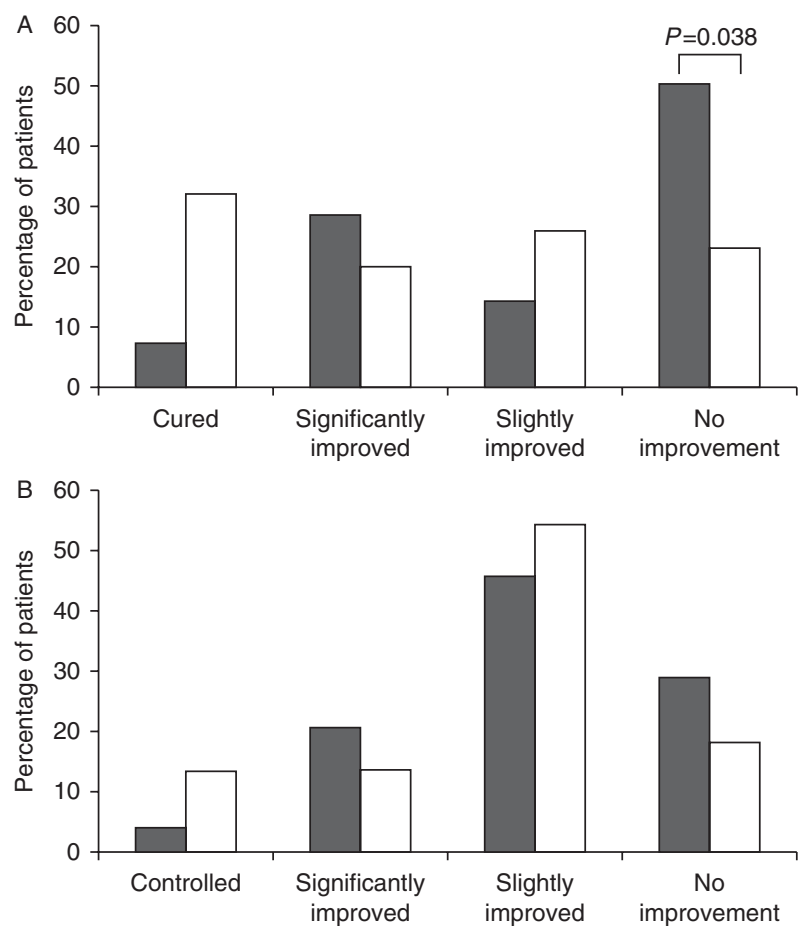

\section{Figure 1}

Outcome data in 126 PA patients with adrenalectomy $(A)$ or medical therapy (B) depending on post-SIT aldosterone values at diagnosis. Group 1 (black bars), post-SIT aldosterone levels of 50-100 ng/l and group 2 (white bars), post-SIT aldosterone levels of $>100 \mathrm{ng} / \mathrm{l}$. Cured (adrenalectomy patients only) = serum potassium $>3.4 \mathrm{mmol} / \mathrm{l}$ and systolic blood pressure $<140 \mathrm{mmHg}$ and diastolic blood pressure $<90 \mathrm{mmHg}$ and no antihypertensives. Controlled (medically treated patients only) $=$ serum potassium $>3.4 \mathrm{mmol} / \mathrm{l}$ and systolic blood pressure $<140 \mathrm{mmHg}$ and diastolic blood pressure $<90 \mathrm{mmHg}$ and on therapy with MR-antagonists, but no other antihypertensives §. Significantly improved $=$ normokalemia and systolic blood pressure decrease by $\geq 10 \mathrm{mmHg}$ and decrease of antihypertensives by $\geq 1 \S$. Slightly improved $=$ normokalemia and systolic blood pressure decrease by $\geq 10 \mathrm{mmHg}$ or decrease of antihypertensives by $\geq 1 \S$. No improvement $=$ persistent hypokalemia or no blood pressure improvement. §, MR antagonist was not counted as an antihypertensive.

A recent study (24) investigating unilateral adrenalectomy in bilateral primary hyperaldosteronism has shown that hypertension was cured in $15 \%$ of patients and improved in 20\%. Also the proportion with controlled hypertension was significantly higher after adrenalectomy (65\%) than before $(25 \%)$. This suggests that unilateral adrenalectomy might be beneficial in some patients with bilateral disease (24), which should not be ruled out per se regarding the rather disappointing outcome data in our cohort.

Our cure/controlled rate is similar to that of a small study with 24 PA patients who showed a cure rate of 33\% after adrenalectomy (25). Possible reasons for the overall rather low cure rate in our study may be the long-lasting insufficiently treated hypertension due to delayed diagnosis in patients with PA. Other studies, which reported a better outcome (23), usually used only one outcome parameter, e.g. BP, and used often less strict definitions for 'cure' such as a BP <160/95 mmHg (26). In an Italian study with 50 patients who underwent adrenalectomy, the BP outcome was 30\% in remission, 53\% markedly improved, and 18\% showing mild improvement (27). These outcome rates might again be better than in our series due to the shorter duration of hypertension and due to the less stringent definition of outcome.

A recent paper by Steichen et al. (28) has summarized the studies on outcome of adrenalectomy in PA patients and calculated a pooled cure rate of $42 \%$ regarding BP as the only outcome parameter, and with significant heterogeneity across the series. In fact, hardly any study has provided a combined outcome analysis of BP and antihypertensive medication. However, the authors pointed out that adrenalectomy usually results in a significant decrease in systolic BP and in the number of antihypertensive medications prescribed (29). Steichen et al. (28) analyzed adrenalectomy series in PA patients also regarding factors influencing the outcome, which were also highly variable among the studies. However, factors which seem to have a significant negative effect on the outcome were male sex, older age, family history of hypertension, longer duration of hypertension, higher preoperative $\mathrm{BP}$, more drug classes, higher BMI, higher serum potassium concentrations, lower estimated glomerular filtration rate, or higher 24-h urinary aldosterone-to-/ active renin ratio $(21,28)$. In our study, we could confirm that sex, age, and duration of hypertension influence outcome; however, a higher preoperative BP was not relevant in our cohort. Our data suggest that low post-SIT aldosterone levels (50-100 ng/l) may be an additional indicator of less successful outcome. However, this needs to be validated in other cohorts. Sawka et al. (30) suggested that a higher pre-operative ARR might result in a better outcome after adrenalectomy. This is in accordance with our finding showing higher ARR in the group with postSIT aldosterone levels of $>100 \mathrm{ng} / \mathrm{l}$.

The only prediction model validated to date is a study with 100 patients who underwent adrenalectomy for PA with validation in an independent series of 67 patients 
from another center (31). In this study, a high percentage of patients continued to require antihypertensive medications to control their BP. The best predictors for cure of hypertension following adrenalectomy were a number of antihypertensive medications of $\leq 2$, a BMI $\leq 25 \mathrm{~kg} / \mathrm{m}^{2}$, duration of hypertension $\leq 6$ years, female sex (31), and age $(2,30)$. We confirm in our study that male PA patients had a poorer outcome than female patients. Nevertheless, the underlying causes of persistent hypertension after PA therapy remain controversial (28). One additional aspect might be that a patient with treated PA is not immune to essential hypertension.

In conclusion, PA patients with post-SIT aldosterone levels of $>100 \mathrm{ng} / \mathrm{l}$ have a more rapid development of PA caused more frequently by unilateral disease with larger APAs. They showed a better outcome regarding BP, potassium normalization, and reduction in the number of antihypertensive drugs. We suggest that the post-SIT aldosterone level is a predictor for the remission probability of PA post adrenalectomy.

\section{Declaration of interest}

The authors declare that there is no conflict of interest that could be perceived as prejudicing the impartiality of the research reported.

\section{Funding}

This research was supported by the Else Kröner-Fresenius-Stiftung, Germany.

\section{Acknowledgements}

The authors are indebted to Kathrin Zopf and Christiane Friedrich, Clinical Endocrinology, Charité Campus Mitte, University Medicine Berlin, for their help with patients' recruitments. The authors wish to thank Susanne Schmid, Friederike Konrad, Nina Nirschl, and Brigitte Mauracher for excellent assistance. We also express our gratitude to the other centers of the study for the collaboration, especially ENS@T centers and Maria-Christina Zennaro, INSERM, UMRS_970, Paris Cardiovascular Research Center, Paris, France.

\section{References}

1 Hannemann A, Bidlingmaier M, Friedrich N, Manolopoulou J, Spyroglou A, Volzke H, Beuschlein F, Seissler J, Rettig R, Felix SB et al. Screening for primary aldosteronism in hypertensive subjects: results from two German epidemiological studies. European Journal of Endocrinology 2012167 7-15. (doi:10.1530/EJE-11-1013)

2 Mulatero P, Monticone S, Bertello C, Viola A, Tizzani D, Iannaccone A, Crudo V, Burrello J, Milan A, Rabbia F et al. Long-term cardio- and cerebrovascular events in patients with primary aldosteronism. Journal of Clinical Endocrinology and Metabolism 201398 4826-4833. (doi:10.1210/jc.2013-2805)

3 Rossi GP, Bernini G, Desideri G, Fabris B, Ferri C, Giacchetti G, Letizia C, Maccario M, Mannelli M, Matterello MJ et al. Renal damage in primary aldosteronism: results of the PAPY Study. Hypertension 200648 232-238. (doi:10.1161/01.HYP.0000230444.01215.6a)

4 Born-Frontsberg E, Reincke M, Rump LC, Hahner S, Diederich S, Lorenz R, Allolio B, Seufert J, Schirpenbach C, Beuschlein F et al. Cardiovascular and cerebrovascular comorbidities of hypokalemic and normokalemic primary aldosteronism: results of the German Conn's Registry. Journal of Clinical Endocrinology and Metabolism 200994 1125-1130. (doi:10.1210/jc.2008-2116)

5 Milliez P, Girerd X, Plouin PF, Blacher J, Safar ME \& Mourad JJ. Evidence for an increased rate of cardiovascular events in patients with primary aldosteronism. Journal of the American College of Cardiology 200545 1243-1248. (doi:10.1016/j.jacc.2005.01.015)

6 Quinkler M, Born-Frontsberg E \& Fourkiotis VG. Comorbidities in primary aldosteronism. Hormone and Metabolic Research 201042 429-434. (doi:10.1055/s-0029-1243257)

7 Savard S, Amar L, Plouin PF \& Steichen O. Cardiovascular complications associated with primary aldosteronism: a controlled cross-sectional study. Hypertension 201362 331-336. (doi:10.1161/HYPERTENSIONAHA.113.01060)

8 Funder JW, Carey RM, Fardella C, Gomez-Sanchez CE, Mantero F, Stowasser M, Young WF Jr \& Montori VM. Case detection, diagnosis, and treatment of patients with primary aldosteronism: an Endocrine Society clinical practice guideline. Journal of Clinical Endocrinology and Metabolism 200893 3266-3281. (doi:10.1210/ jc.2008-0104)

9 Rossi GP, Belfiore A, Bernini G, Desideri G, Fabris B, Ferri C, Giacchetti G, Letizia C, Maccario M, Mallamaci F et al. Prospective evaluation of the saline infusion test for excluding primary aldosteronism due to aldosterone-producing adenoma. Journal of Hypertension 200725 1433-1442. (doi:10.1097/HJH.0b013e328126856e)

10 Kem DC, Weinberger MH, Mayes DM \& Nugent CA. Saline suppression of plasma aldosterone in hypertension. Archives of Internal Medicine 1971128 380-386. (doi:10.1001/archinte.1971.00310210056004)

11 Holland OB, Brown H, Kuhnert L, Fairchild C, Risk M \& Gomez-Sanchez CE. Further evaluation of saline infusion for the diagnosis of primary aldosteronism. Hypertension 19846 717-723. (doi:10.1161/01.HYP.6.5.717)

12 Giacchetti G, Ronconi V, Lucarelli G, Boscaro M \& Mantero F. Analysis of screening and confirmatory tests in the diagnosis of primary aldosteronism: need for a standardized protocol. Journal of Hypertension 200624 737-745. (doi:10.1097/01.hjh.0000217857.20241.0f)

13 Schirpenbach C, Segmiller F, Diederich S, Hahner S, Lorenz R, Rump LC, Seufert J, Quinkler M, Bidlingmaier M, Beuschlein F et al. The diagnosis and treatment of primary hyperaldosteronism in Germany: results on 555 patients from the German Conn Registry. Deutsches Ärzteblatt International 2009106 305-311. (doi:10.3238/arztebl.2009.0305)

14 Fourkiotis V, Vonend O, Diederich S, Fischer E, Lang K, Endres S, Beuschlein F, Willenberg HS, Rump LC, Allolio B et al. Effectiveness of eplerenone or spironolactone treatment in preserving renal function in primary aldosteronism. European Journal of Endocrinology 2012168 75-81. (doi:10.1530/EJE-12-0631)

15 Fischer E, Beuschlein F, Bidlingmaier M \& Reincke M. Commentary on the Endocrine Society Practice Guidelines: Consequences of adjustment of antihypertensive medication in screening of primary aldosteronism. Reviews in Endocrine \& Metabolic Disorders 201112 43-48. (doi:10.1007/s11154-011-9163-7)

16 Reincke M, Rump LC, Quinkler M, Hahner S, Diederich S, Lorenz R, Seufert J, Schirpenbach C, Beuschlein F, Bidlingmaier M et al. Risk factors associated with a low glomerular filtration rate in primary aldosteronism. Journal of Clinical Endocrinology and Metabolism 200994 869-875. (doi:10.1210/jc.2008-1851)

17 Vonend O, Ockenfels N, Gao X, Allolio B, Lang K, Mai K, Quack I, Saleh A, Degenhart C, Seufert J et al. Adrenal venous sampling: evaluation of the German Conn's Registry. Hypertension 201157 990-995. (doi:10.1161/HYPERTENSIONAHA.110.168484) 
18 Beuschlein F, Boulkroun S, Osswald A, Wieland T, Nielsen HN, Lichtenauer UD, Penton D, Schack VR, Amar L, Fischer E et al. Somatic mutations in ATP1A1 and ATP2B3 lead to aldosterone-producing adenomas and secondary hypertension. Nature Genetics $2013 \mathbf{4 5}$ 440-442. (doi:10.1038/ng.2550)

19 Fernandes-Rosa FL, Williams TA, Riester A, Steichen O, Beuschlein F, Boulkroun S, Strom TM, Monticone S, Amar L, Meatchi T et al. Genetic spectrum and clinical correlates of somatic mutations in aldosteroneproducing adenoma. Hypertension 201464 354-361. (doi:10.1161/ HYPERTENSIONAHA.114.03419)

20 Mulatero P, Milan A, Fallo F, Regolisti G, Pizzolo F, Fardella C, Mosso L, Marafetti L, Veglio F \& Maccario M. Comparison of confirmatory tests for the diagnosis of primary aldosteronism. Journal of Clinical Endocrinology and Metabolism 200691 2618-2623. (doi:10.1210/jc. 2006-0078)

21 van der Linden P, Steichen O, Zinzindohoue F \& Plouin PF. Blood pressure and medication changes following adrenalectomy for unilateral primary aldosteronism: a follow-up study. Journal of Hypertension 201230 761-769. (doi:10.1097/HJH. 0b013e328350225d)

22 Akerstrom T, Crona J, Delgado VA, Starker LF, Cupisti K, Willenberg HS, Knoefel WT, Saeger W, Feller A, Ip J et al. Comprehensive re-sequencing of adrenal aldosterone producing lesions reveal three somatic mutations near the KCNJ5 potassium channel selectivity filter. PLOS ONE 20127 e41926. (doi:10.1371/journal.pone. 0041926)

23 Wang W, Hu W, Zhang X, Wang B, Bin C \& Huang H. Predictors of successful outcome after adrenalectomy for primary aldosteronism. International Surgery 201297 104-111. (doi:10.9738/CC140.1)

24 Sukor N, Gordon RD, Ku YK, Jones M \& Stowasser M. Role of unilateral adrenalectomy in bilateral primary aldosteronism: a 22-year single center experience. Journal of Clinical Endocrinology and Metabolism 2009 94 2437-2445. (doi:10.1210/jc.2008-2803)

25 Meyer A, Brabant G \& Behrend M. Long-term follow-up after adrenalectomy for primary aldosteronism. World Journal of Surgery 2005 29 155-159. (doi:10.1007/s00268-004-7496-z)

26 Celen O, O'Brien MJ, Melby JC \& Beazley RM. Factors influencing outcome of surgery for primary aldosteronism. Archives of Surgery 1996 131 646-650. (doi:10.1001/archsurg.1996.01430180072015)

27 Rossi GP, Bolognesi M, Rizzoni D, Seccia TM, Piva A, Porteri E, Tiberio GA, Giulini SM, Agabiti-Rosei E \& Pessina AC. Vascular remodeling and duration of hypertension predict outcome of adrenalectomy in primary aldosteronism patients. Hypertension $2008 \mathbf{5 1}$ 1366-1371. (doi:10.1161/HYPERTENSIONAHA.108.111369)

28 Steichen O, Zinzindohoue F, Plouin PF \& Amar L. Outcomes of adrenalectomy in patients with unilateral primary aldosteronism: a review. Hormone and Metabolic Research 201244 221-227. (doi:10.1055/ s-0031-1299681)

29 Utsumi T, Kawamura K, Imamoto T, Kamiya N, Nagano H, Tanaka T, Nihei N, Naya Y, Suzuki H \& Ichikawa T. Assessment of postoperative changes in antihypertensive drug consumption in patients with primary aldosteronism using the defined daily dose. Asian Journal of Surgery 201437 190-194. (doi:10.1016/j.asjsur.2014.01.011)

30 Sawka AM, Young WF, Thompson GB, Grant CS, Farley DR, Leibson C \& van Heerden JA. Primary aldosteronism: factors associated with normalization of blood pressure after surgery. Annals of Internal Medicine 2001135 258-261. (doi:10.7326/0003-4819-135-4200108210-00010)

31 Zarnegar R, Young WF Jr, Lee J, Sweet MP, Kebebew E, Farley DR, Thompson GB, Grant CS, Clark OH \& Duh QY. The aldosteronoma resolution score: predicting complete resolution of hypertension after adrenalectomy for aldosteronoma. Annals of Surgery 2008247 511-518. (doi:10.1097/SLA.0b013e318165c075)

Received 21 November 2014

Revised version received 18 January 2015

Accepted 28 January 2015 